Document downloaded from:

http://hdl.handle.net/10251/167204

This paper must be cited as:

Guardiola, C.; Pla Moreno, B.; Bares-Moreno, P.; Mora, J. (2020). An on-board method to estimate the light-off temperature of diesel oxidation catalysts. International Journal of Engine Research. 21(8):1480-1492. https://doi.org/10.1177/1468087418817965

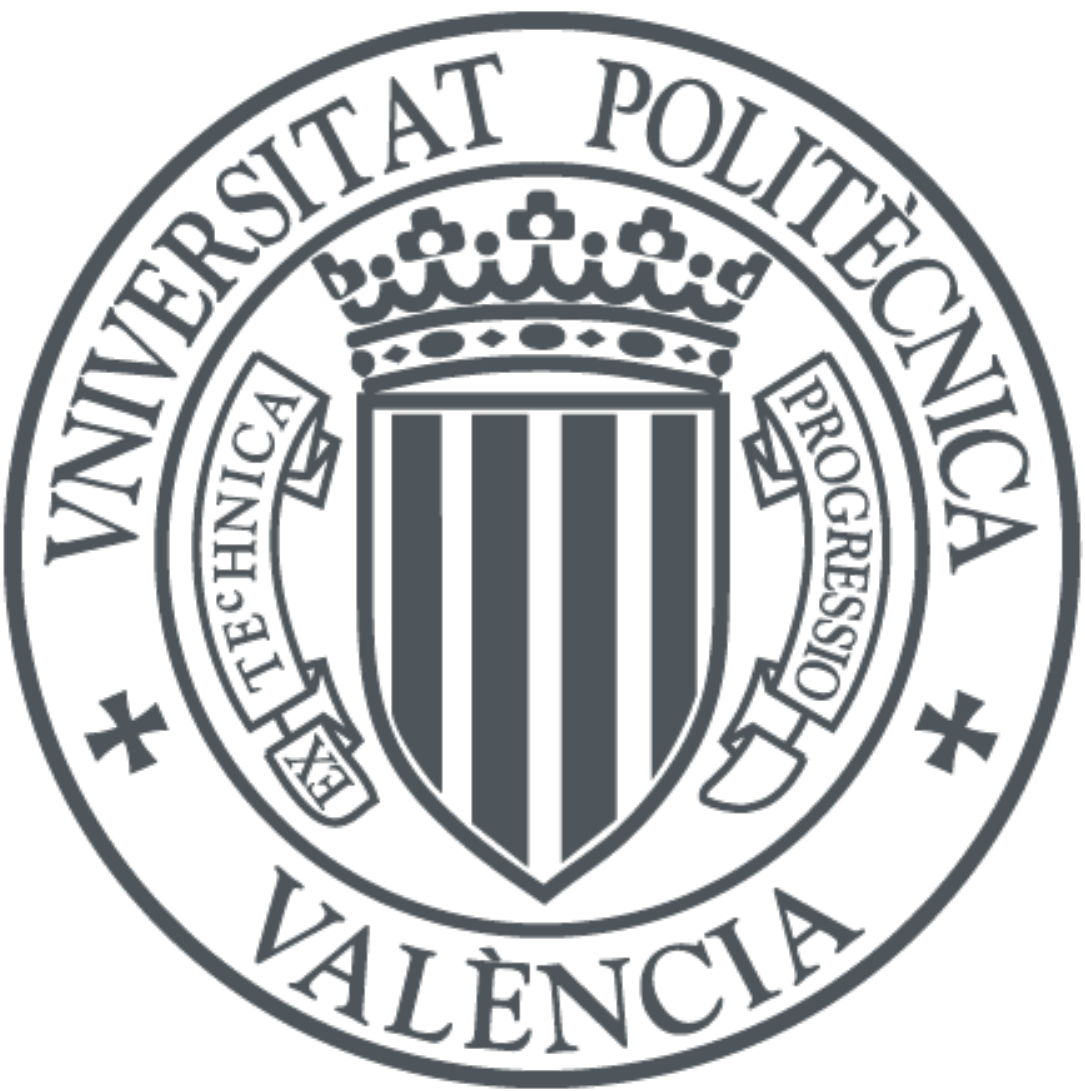

The final publication is available at

https://doi.org/10.1177/1468087418817965

Copyright SAGE Publications

Additional Information 


\title{
An on-board method to estimate the light-off temperature of diesel oxidation catalysts
}

\author{
C. Guardiola ${ }^{1}$ and B. Pla ${ }^{1}$ and P. Bares ${ }^{1} \mathrm{~J}^{-}$Mora ${ }^{1}$
}

\begin{abstract}
Current Diesel engines regulations include on-board diagnostics requirements, so that after-treatment systems need on-board methods to detect its ageing state through the available measurements. In a state-of-the-art diesel exhaust line, two temperature and $\lambda$ measurements can be found up- and downstream the diesel oxidation catalyst. Thus, the strategy presented in this paper makes use of these measurements to estimate the light-off temperature, which has been widely studied as a characteristic of diesel oxidation catalysts ageing. The light-off temperature estimation potential is evaluated first in dynamic engine operating conditions, in which $\lambda$ measurements are proved to be precise enough to detect oxidation. However, dynamic conditions difficult the association of a representative temperature to an oxidation event. Therefore, the method makes use of more controlled conditions at idle, during which the exhaust temperature decreases avoiding dynamics of normal driving conditions. During idle, post-injection pulses are applied to determine whether oxidation occurs at a representative temperature measured by the upstream temperature sensor. The result of each pulse is used to generate a database. Then, after a long enough time window, the database generated will allow characterizing non-oxidation and oxidation temperatures, with an intermediate interval of indefinition. The present paper shows how the temperatures of these ranges increase as the light-off temperature increases, then validating the proposed method for light-off temperature estimation.
\end{abstract}

\section{Keywords}

diesel oxidation catalyst diagnosis, catalyst ageing, light-off temperature, ageing estimation, Diesel engine emissions

\section{Introduction}

After-treatment systems play an important role in the reduction of tailpipe emissions of Diesel engines. However, the ageing of the emissions control systems lead to an increase of the pollutant species, which is accounted in worldwide regulations through on-board diagnostics (OBD) protocols ${ }^{1,2}$. Current diagnosis standards consider the detection of a complete fault for diesel oxidation catalysts (DOC) ${ }^{3}$. In this line, real driving emissions (RDE), measured through portable emissions measurements systems $(\text { PEMS })^{4}$, complement the recent world harmonized lightduty test procedure (WLTP $)^{5}$. Then, following the trend over the last years, more requirements will be necessary to ensure emission thresholds are respected ${ }^{6,7}$. This paper presents an on-board methodology to estimate the light-off temperature (LOT) of a diesel oxidation catalyst (DOC), whose increment is an effect of aging and it is associated to an emissions increase.

Light-off temperature is a characteristic of DOCs that marks the temperature, or range of temperatures, from which a DOC starts having oxidation activity. The LOT has been widely analyzed in literature, being ${ }^{8}$ and ${ }^{9}$ some examples in which the LOT is defined at $50 \%$ oxidation of the upstream $\mathrm{HC}$ species. However, if HC species are not measured, an indirect estimation of the LOT has to be done. The LOT increase is considered as a result of the DOC ageing, which results in an emissions increase in aged catalysts, mainly affecting $\mathrm{HC}, \mathrm{CO}$ and the $\mathrm{NO}$ to $\mathrm{NO}_{2}$ conversion ${ }^{10,11}$, as Figure 1 shows. For this figure, the slip of $\mathrm{HC}$ and $\mathrm{CO}$ is considered as the integration of the downstream species while the DOC upstream temperature $T_{u s}$ is under and over the LOT, over the integration of the upstream species during the same intervals than for the downsream species. The LOT of the new DOC defined at $200^{\circ} \mathrm{C}$ and the LOT of the aged DOC is defined at $250^{\circ} \mathrm{C}$. An analogic procedure is done for the $\mathrm{NO} / \mathrm{NO}_{\mathrm{x}}$ conversion. In this WLTC test, the difference in average $\mathrm{HC}$ and $\mathrm{CO}$ slip while $T_{u s}$ is under and over LOT is more pronounced for the aged DOC than when the DOC is in new conditions. Moreover in the WLTC, the $T_{u s}$ is under LOT during $48 \%$ of time for the new DOC, while the $T_{u s}$ is under LOT during $74 \%$ of time for the aged DOC. Therefore, estimating the LOT allows having an indicator of the DOC ageing effect on emissions, so the electronic control unit can apply the corresponding thermal management strategy or diagnostics solution.

As ageing mechanisms, excessive temperatures above $600^{\circ} \mathrm{C}$ and sulfur poisoning are the two main ageing causes $^{12}$. In fact, exposure to high temperatures is considered as a valid ageing method for regulation validations ${ }^{13}$.

\footnotetext{
${ }^{1}$ CMT-Motores Térmicos, Universitat Politècnica de València, Valencia, Spain
}

\section{Corresponding author:}

Javier Mora, CMT-Motores Térmicos, Universitat Politècnica de València, Camino de Vera Sn, E-46022 Valencia, Spain

Email: jamopre1@mot.upv.es 

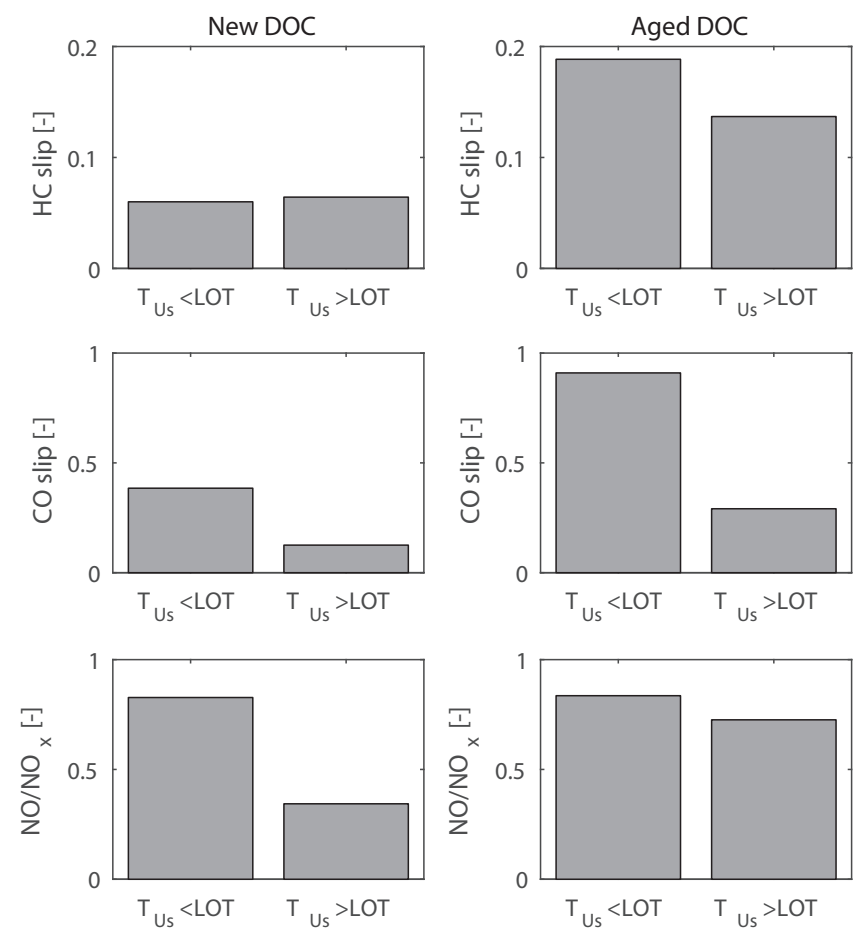

Figure 1. Importance of LOT on emissions, described through emissions slip over engine-raw emissions, when DOC upstream temperature is under and over LOT in a WLTC starting at around $22^{\circ} \mathrm{C}$. Engine raw emissions are considered for each case taking into account also the DOC upstream temperature.

The on-board estimation of the LOT is subjected to the particular after-treatment system layout, which is composed of catalysts and sensors. Despite the high potential of LOT estimation for DOC diagnosis and engine thermal management, no sensors are available to measure the concentration species mainly affected by the LOT increase. In this line, emissions models for DOCs are complex to apply without proper measurements of species. Moreover, DOC models have such level of complexity that maps based models like ${ }^{14}$ are considered a useful tool for calibration and control. However, ageing is not considered in the models available in literature, while an ageing function would be necessary to apply DOC models with transition states from new to aged pieces. The addition of the ageing function, nevertheless, would add more complexity to the model. For these reasons, LOT estimation or DOC efficiency estimation based on emissions models, seem difficult to be implemented for on-board applications. Then, in order to estimate the LOT, the use of non model based techniques becomes a suitable alternative. In this paper, idle is used as a steady engine operating point at low temperature ${ }^{15}$, which allows having more controlled conditions during the temperature transition through the LOT.

The state-of-the-art after-treatment system for Euro VI combustion ignition engines is composed of a DOC at the engine outlet, followed by a diesel particulate filter (DPF) and a deNO ${ }_{x}$ system like the lean $\mathrm{NO}_{\mathrm{x}}$ trap (LNT) or the selective catalytic reduction system $(\mathrm{SCR})^{16}$. The DOC is placed at the front for the impact that has on DPF and SCR performance ${ }^{17,18}$. The urea injection of the SCR is placed right before the SCR, so it does not have interference with the DOC. Then, a set of sensors is used to control and diagnose
Table 1. Engine main characteristics.

\begin{tabular}{ll}
\hline Stroke (S) & $88 \mathrm{~mm}$ \\
Bore (D) & $85 \mathrm{~mm}$ \\
S/D & 1.035 \\
Number of cylinders (z) & 4 \\
Displacement & $1997 \mathrm{cc}$ \\
Compression ratio & $16: 1$ \\
Valves by cylinder & 4 \\
Maximum power & $120 \mathrm{~kW} @ 3750 \mathrm{rpm}$ \\
\hline
\end{tabular}

the system ${ }^{19,20}$ : two temperature sensors are placed up- and downstream the $\mathrm{DOC}^{3}$, a $\mathrm{NO}_{\mathrm{x}}$ sensor is placed after the SCR to control the urea injection and for diagnosis ${ }^{16,21}$, while the sensor at the turbine outlet may depend on the vehicle, which can be a $\lambda$ sensor, a $\mathrm{NO}_{\mathrm{x}}$ sensor or even a model ${ }^{22,23}$.

Oxygen concentration measurements, required for the purpose of this paper, can be obtained from $\mathrm{NO}_{\mathrm{x}}$ sensors or universal exhaust gas oxygen (UEGO) sensors, since current planar zirconia multilayer $\mathrm{NO}_{x}$ sensors simultaneously provide air-to-fuel-ratio $(\lambda)$ and $\mathrm{NO}_{\mathrm{x}}$ concentration ${ }^{24}$. A pair of $\mathrm{NO}_{\mathrm{x}}$ sensors was used in this paper.

The strategy presented is based on the capacity of the $\mathrm{NO}_{\mathrm{x}}$ sensors to detect oxidation events through $\lambda$ measurements. Then, the strategy makes use of the upstream temperature sensor to associate oxidation events to representative temperatures and generate a database, which will be evaluated to establish the no-oxidation to oxidation ranges. Note that this strategy makes use of the state-of-the-art set of sensors present in a complete after-treatment system of a diesel exhaust line. An analogic method could be used for lean $\mathrm{NO}_{\mathrm{x}}$ trap (LNT) systems, which accumulate and reduce $\mathrm{NO}_{\mathrm{x}}$ species, although this is out of the scope of this paper.

This paper is structured as follows: the introduction presents the motivation and necessary background, then the experimental set-up is presented, next the detection concept feasibility is shown, in which a dynamic case is presented and the fundamentals of the method are described, next the sensors requirements and capacities are detailed, then the strategy is evaluated with the LOT estimation and conclusions are finally presented in the last section.

\section{Experimental set-up}

Several experimental tests are presented in this paper, which were carried out in a Euro V Diesel engine coupled to an engine bench. Table 1 shows relevant characteristics of the engine, which was composed of a high-pressure common rail diesel injection system, an Exhaust Gas Recirculation (EGR) system and a Variable Geometry Turbine (VGT). As the main objective of this paper is to estimate the light-off temperature of a DOC, two different catalysts were used, each one with a different level of ageing and therefore, different LOTs. The DOC was the only after-treatment system placed in the exhaust line.

A bypass was made to the engine ECU by means of an ETAS 910 and a rapid prototyping system dSpace Microautobox II. In this sense, the injection strategy was adapted in order to inject raw fuel in the exhaust line through late post-injections. The signals for the post-injections were generated from the rapid prototyping system dSpace, making 


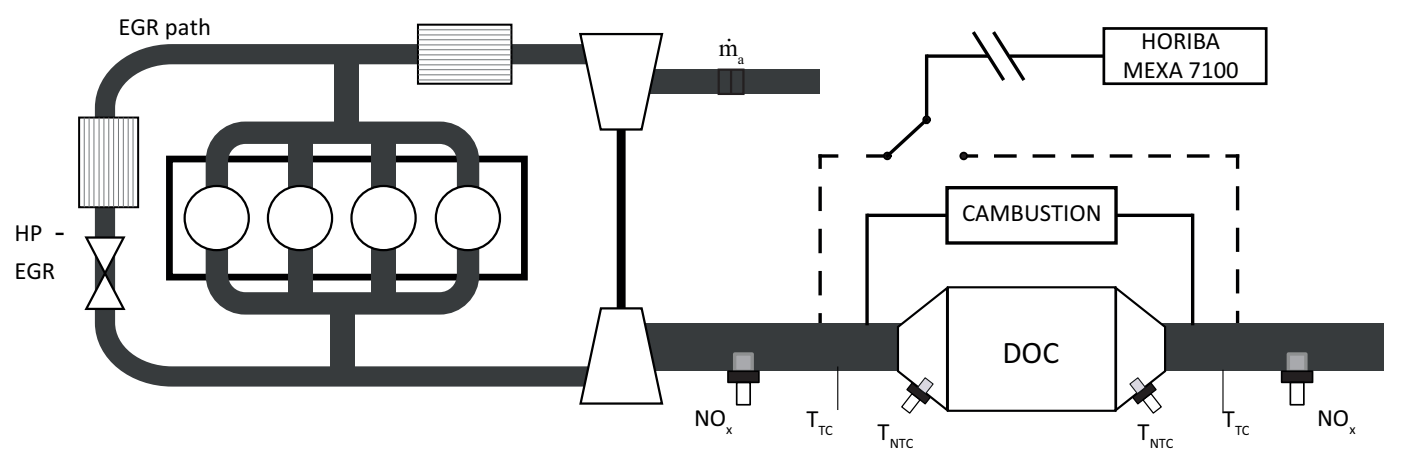

Figure 2. Test bench set-up.

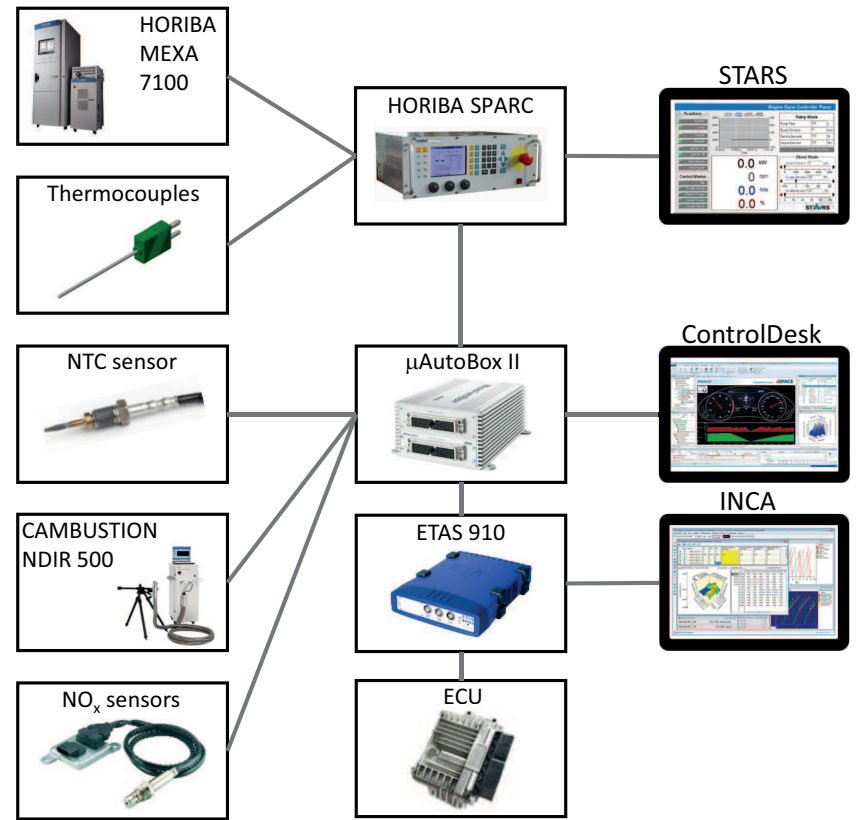

Figure 3. Scheme of hardware connections in the test bench.

pulses of different duration and amplitude, at a constant start of injection (SOI). A Horiba STARS system was used to control the engine operating conditions and acquire data. Figure 3 schematize the previously cited connections.

To analyze the exhaust gases and validate the sufficient measurement capabilities of the on-board sensors for the strategy requirements, an intensive measurement system in the exhaust line was used. A Horiba Mexa 7100 series was used to measure the up- and downstream DOC THC concentration through a heated vacuum-type flame ionization detector (HFID) procedure. A switch was used in order to distinguish between up- and downstream measurements, for which separate tests had to be carried out. Its time response is limited by the own measurement procedure and the long distance between the engine line and the measurement unit. Therefore, a Cambustion exhaust gas analyzer was used to validate $\lambda$ measurements from the $\mathrm{NO}_{\mathrm{x}}$ sensors. Two $\mathrm{NO}_{\mathrm{x}}$ sensors were used to measure the up- and downstream DOC $\lambda$ values. These sensors have an inherent offset in their measurements, which is quantified in Figure 4 through 22 steady-state measurements in a wide range of oxygen concentrations. The Horiba gas analyzer system was connected to the STARS acquisition system, while the Cambustion fast gas anlyzer and the $\mathrm{NO}_{\mathrm{x}}$ sensors were

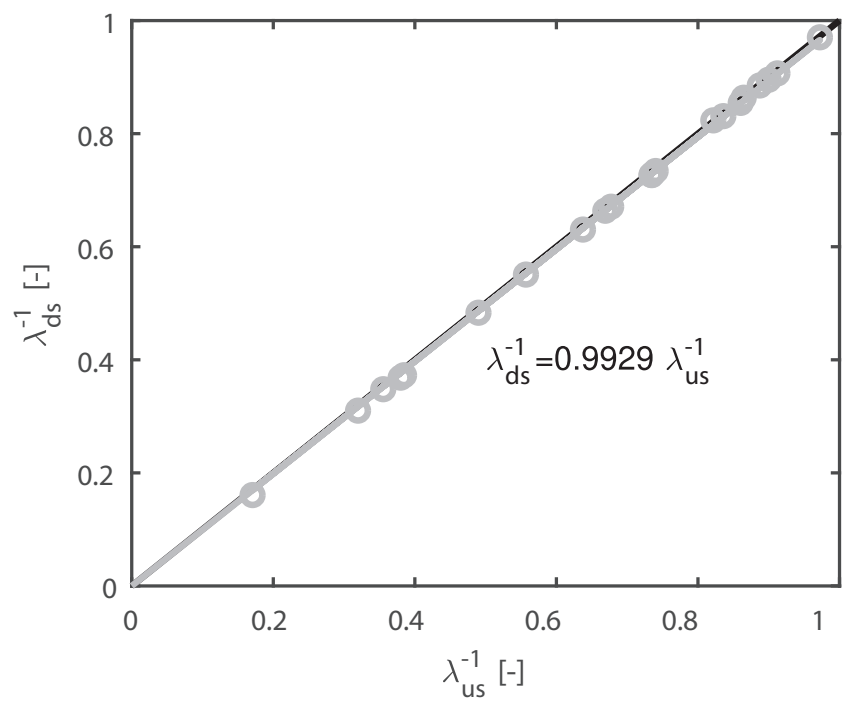

Figure 4. Characterization of the offset between $\lambda$ measurements of the $\mathrm{NO}_{x}$ sensors.

connected to the dSpace system. Note that $\lambda$ measurements, used several times along the paper, are referred to the actual $\lambda$ measured by the $\mathrm{NO}_{\mathrm{x}}$ sensors, and not to the in-cylinder air-to-fuel ratio.

Temperature measurements were done by means of onboard NTC sensors $\mathrm{T}_{N T C}$ and test bench thermocouples $\mathrm{T}_{T C}$. While the Denso NTC sensors were connected to the dSpace system, the thermocouples were connected to the STARS acquisition system. The main difference between the thermoresistance-based NTC sensors and the thermocouples was in the thermal inertia, since NTC sensors are heavier due to its required robustness for in-vehicle applications. Therefore, NTC measurements are slower than thermocouple measurements. The NTC sensors were located up- and downstream the DOC core, and the thermocouples were connected in the DOC manifolds, near the joint.

A set of two catalysts was used, including a nominal and an aged catalyst, with different light-off temperatures. Both catalysts had the same specifications in brand new conditions, although different ageing procedures have been applied. The nominal catalyst is a catalyst with hundreds of hours of use, without presence of high temperature phases, i.e. without exceeding $600^{\circ} \mathrm{C}$. On the other hand, an articificial ageing procedure was applied to the aged catalyst through exposure to high temperatures, i.e. temperature over 
$800^{\circ} \mathrm{C}$ during more than $20 \mathrm{~h}$ hours in an oven. Then, these two catalysts will be used to have different LOT to estimate.

\section{Detection concept feasibility}

The LOT estimation strategy is based on the difference between up- and downstream oxygen concentrations during oxidation phases, and the association of a representative temperature to the oxidation event. Several aspects should be considered for this strategy, accounting for the sensors precision, dynamics and offsets, as well as the own DOC dynamics, its ageing state and engine operating conditions. In this sense, the $\lambda$ measurements must be fast and precise enough to capture the difference in oxygen concentration that an oxidation event produces. Then, the temperature associated to oxidation can come from the temperature measurement or from a model estimating the DOC inlet temperature.

First, the potential to estimate the LOT without neither controlled engine operating situation nor excitation with post-injections is evaluated. For this purpose, a dynamic case is presented to outline the possibilities and limitations of the system during normal engine operating conditions. This is done with a NEDC test, shown in Figure 5, which was selected because the effect that different LOTs has on oxidation events can be appreciated. For this purpose, oxidation events are compared for the nominal and aged DOCs. A thresholds-based method, not suitable for on-board purposes, was used for this dynamic detection. In order to compare the up- and downstream $\lambda$ measurements, a delay model depending on the exhaust mass flow was used to compensate the delay due to the travel time of the species between up and downstream locations. This delay model is composed of the following equations:

$$
\begin{gathered}
a=\left(\tau_{\max }-\tau_{\min }\right)^{n} /\left(\dot{m}_{e x h, \max }-\dot{m}_{e x h, \min }\right)^{n} \\
c=a *\left(\dot{m}_{e x h, \max }-\dot{m}_{e x h, \min }\right)^{n} \\
\tau=\tau_{\min }+ \\
\left(c-a *\left(\min \left\{\dot{m}_{e x h, f i l t}, \dot{m}_{e x h, \max }\right\}-\dot{m}_{e x h, \min }\right)^{n}\right)^{(1 / n)}
\end{gathered}
$$

where $\tau$ is the applied delay, which needs to be filtered to avoid back steps in time, and $\tau_{\max }, \tau_{\min }, \dot{m}_{e x h, \max }$ and $\dot{m}_{\text {exh,min }}$ are calibrable parameters.

In normal operating conditions, $\lambda$ measurements are responsible for detecting raw oxidation events. If the difference between both sensors measurements is higher than a certain threshold, oxidation is assumed to be occurring. Excessive dynamic phases are avoided with a threshold for the derivative of the $\lambda$ measurements. Otherwise, dynamics effects on differences between up and downstream $\lambda$ measurements would lead to errors. Next, once oxidation is observed, a representative temperature should be associated to oxidation. By repeating this procedure several times at different temperatures, a database like the schematic Figure 6 is to be generated.

The NEDC is used as a dynamic cycle to observe oxidation phases with $\lambda$ measurements. Since the NEDC is not as dynamic as the WLTC, it has phases under and over the LOT, as the WLTC also has, while the oxidation phases can still be well appreciated. During phases in which the engine is running below the LOT, the DOC is being filled with raw $\mathrm{HC}$ species. Then, due to the 4 temperature peaks of the urban phase of the NEDC in Figure 5, 4 oxidation events can be appreciated for the nominal catalyst, while oxidation starts at the extra-urban phase for the aged catalyst, when the temperature increase is higher. Note that the urban phase oxidation events do not appear in the test with the aged DOC. In both cases, despite the dynamic conditions of the $\lambda$ measurements, oxidation events can be captured, since the excitation is sufficiently high. However, the difference in sensors measurements is subjected to sensors offset, so that a non-adaptive calibration would not be able to overcome sensor-to-sensor offset issues.

Another problem present during dynamic conditions is that even if the nominal and aged catalysts have different LOT, the measured temperature during the oxidation event at the extra-urban step is similar for both DOCs. In fact, it is higher for the nominal DOC, approximately more than $300{ }^{\circ} \mathrm{C}$, than for the aged DOC, approximately less than $300{ }^{\circ} \mathrm{C}$. Therefore, the feasibility of associating a representative temperature to each DOC is low. Moreover, there is no control over the temperature, since it is subjected to particular driving conditions. Post-injections could be applied during low temperature phases to increase the level of excitation and therefore increase the $\lambda$ difference, although the temperature step problem would remain.

Summarizing, the LOT estimation in dynamic conditions has the following drawbacks, which cannot be overcome for on-board applications:

- The thresholds-based calibration is subjected to sensors offset. A different pair of sensors could need different threshold values.

- In case of an oxidation event is detected, a representative temperature could not be associated, since temperature is highly unsteady in dynamic conditions.

- The required temperature to fill the database cannot be provoked, since temperature is subjected to particular driving conditions.

In order to overcome these problems, the strategy proposed in this paper makes use of idling and postinjections to generate decision events. Idle periods are characterized by low temperatures at steady state conditions, since the fuel injected is low. Note that idling is not the lowest temperature achievable because tip-off events and near-drag conditions can have lower temperatures. Regarding the priorto-idle engine operating conditions, the initial engine-raw temperature has to be above the LOT to observe oxidation events. A non controllable and limiting aspect is the idle timing, since it has to be enough to apply the post-injection pulses and allow the temperature to decrease. For instance, a vehicle running that stops at a red light, or a vehicle that comes out from the highway and park during a moment, would be potential cases to apply the strategy. For this reason, the use of embedded GPS systems and smart city connections can help to decide the suitable moments, since they can predict if the engine will be enough time at idling. 

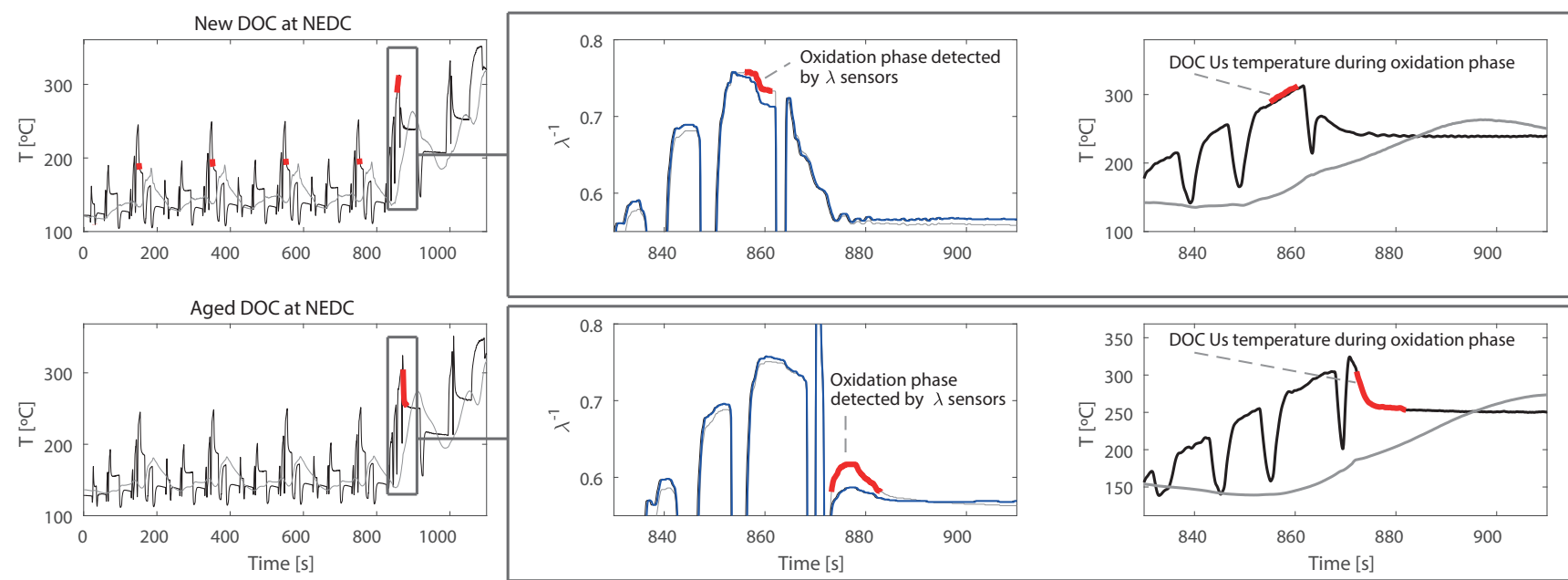

Figure 5. Detection of oxidation phases in dynamic conditions with $\lambda$ measurements at an NEDC cycle for a nominal DOC (top plots) and an aged DOC (bottom plots). Central and right plots are a zoom of the oxidation event at the extra-urban step. Left and right plots: upstream temperature is black, downstream temperature is grey, temperature during oxidation is red. Central plot: upstream delayed $\lambda$ is blue, downstream $\lambda$ is grey and oxidation phase is red.

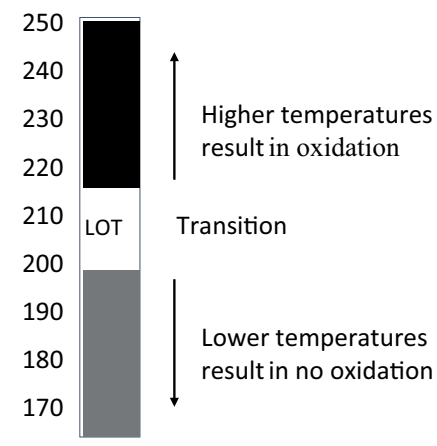

Figure 6. Strategy scheme.

In order to decide whether the DOC is able to oxidize or not at a certain temperature, post-injection pulses are applied. Then, post-injection pulses can be applied as long as the temperature is appropriate, since a database of postinjections at different temperatures has to be generated. If the temperature at which the engine is running prior to idle is above the light-off, the first post-injections will be oxidized. Next, if more post-injection pulses are applied as temperature decreases, the $\lambda$ measurements will reach a threshold from which no oxidation will be detected.

Regarding the constraints of the regulation for DOC diagnosis, it considers an in-use performance ratio (IUPR) of 0.336 . As stated in the Euro regulation ${ }^{25}$, the denumerator must be increased by 1 at least after $800 \mathrm{~km}$, so that the strategy can collect cases during $2400 \mathrm{~km}$, when the LOT estimation would be triggered and the IUPR counter would reset. The regulation also considers an idle period of 30 s as a correct order of magnitude, during which the strategy can at least perform one complete pulse to feed the database ${ }^{25}$.

Figure 7 shows the experimental behaviour in which the strategy is based. It contains a train of post-injection pulses starting at an upstream temperature of $290^{\circ} \mathrm{C}$ and finishing at $180^{\circ} \mathrm{C}$, where the $\lambda$ measurements of the $\mathrm{NO}_{\mathrm{x}}$ sensors can be contrasted with the $\mathrm{HC}, \mathrm{CO}$ and $\mathrm{O}_{2}$ measurements of the Horiba gas analyzer. During the decrease of temperature, it can be appreciated how the $\mathrm{O}_{2}$ consumed during the pulses decreases from a valley of $15.4 \%$ to a valley of $16.2 \%$ due to the loss of oxidation capacity of the catalyst. However, several aspects need to be assessed first in order to understand the $\lambda$ measurements.

As it can be appreciated in Figure 7, both the $\mathrm{HC}$ and $\mathrm{CO}$ measurements are significantly reduced at the DOC downstream during all the test. However, the $\mathrm{O}_{2, \mathrm{ds}}$ valley at every post-injection pulse increases as the the capacity of the DOC decreases, which implies that the oxidation is being reduced by a lower DOC temperature. In this sense, the decrease in oxygen consumed while the downstream HC and $\mathrm{CO}$ emissions are maintained, is explained by the $\mathrm{HC}$ accumulation capacity of the DOC. I.e. the HC species that are not oxidized, are accumulated in the catalyst. Moreover, the $\mathrm{CO}$ oxidation effect in terms of $\mathrm{O}_{2}$ is sensitively less significant than that of the $\mathrm{HC}$ oxidation.

The increasing slip of HC, significant from 100s seconds, denotes the filling process, through which the catalyst is less able to retain $\mathrm{HC}$ and therefore it expulses them. By contrast, although the $\mathrm{CO}$ species are also oxidized during the most part of thest, a first peak appears at the downstream measurement at the end of the test, which is due to the fact that the DOC is reaching its CO LOT, lower than that of the $\mathrm{HC}$, as it is also stated in ${ }^{9}$.

Taking into account the behaviour of the species, it can be stated that the decrease of the $\lambda_{d s}^{-1}$ signal in comparison with the $\lambda_{u s}^{-1}$ along the test is due to the decrease in $\mathrm{HC}$ oxidation capacity of the catalyst. However, two aspects that are assessed in next section must be noted; on one hand, the $\lambda_{u s}^{-1}$ presents peaks despite $\mathrm{O}_{2 \text {,us }}$ oxygen is not significantly affected. In this sense, while the $\mathrm{O}_{2 \text {,us }}$ measurement from the gas analyzer is a measurement of the raw $\mathrm{O}_{2}$,us concentration, the $\lambda$ measurement is, theoretically, a measurement of the oxygen excess, taking into account the oxygen necessary to oxidize $\mathrm{HC}$ and $\mathrm{CO}$ species. On the other hand, the peaks of the $\lambda_{d s}^{-1}$ are still significant at the end of the test, in which $\mathrm{HC}$ oxidation is not significant. 

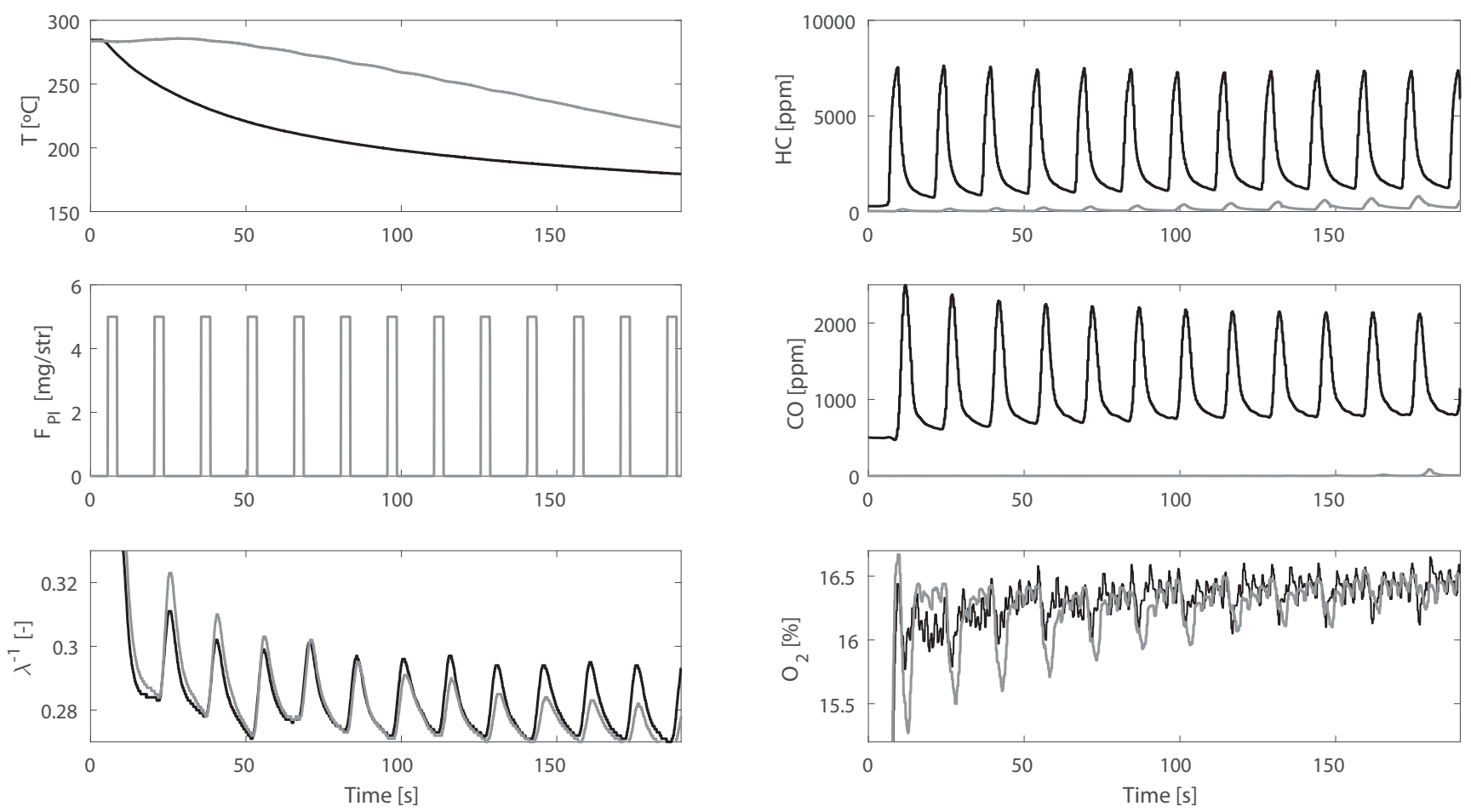

Figure 7. Example of a train of post-injection pulses starting with $\mathrm{HC}$ oxidation and finishing without $\mathrm{HC}$ oxidation, during a phase of decreasing temperature. Offset between upstream and downstream $\lambda$ and $\mathrm{O}_{2}$ measurements is compensated. Upstream: black. Downstream: grey.

\section{On-board measurements characterization}

With the method fundamentals described in the previous section, sensors requirements and their limitations are evaluated in this section. Temperature signals in Figure 7 are obtained from thin thermocouples measurements, to highlight the dynamics problem of the temperature during driving conditions. Temperature evolution is so dynamic that a representative temperature cannot be associated to an oxidation event. In this line, on-board NTC sensors measurements are slower than gas temperature variations, since its robustness requirements implies they have more mass and therefore more thermal inertia. Then, despite the upstream measurement could be improved by means of data fusion techniques as described in $^{26}$, the problem of associating a representative temperature would remain. On the other hand, it is foreseen to have the same location of sensor for all vehicles, so once calibrated, the strategy will not be affected by the sensor position. This consideration takes into account the fact that a temperature measurement is affected by the sensor location due to radiation effects or non-uniform flow distributions, among others.

The $\lambda$ measurements are a key part of the strategy, since they have to measure the decrease in oxygen concentration produced by DOC oxidation. In this sense, their capacity to detect oxidation conditions is next discussed. Dynamic response, accuracy, precision, ageing and capacity to measure oxygen concentration in presence of raw $\mathrm{HC}$ are considered.

Figure 8 represents the dynamics of the $\lambda$ measurements with the $\mathrm{NO}_{\mathrm{x}}$ sensors in comparison with the $\mathrm{CO}_{2}$ measurement from the Cambustion fast gas analyzer. The measurement of the $\mathrm{HC}$ species is shown to represent the effect of the post-injection on $\mathrm{HC}$, but its dynamics are not representative due to the slow measurement of the gas analyzer. The left plots correspond to a post-injection pulse at a high exhaust flow and the right plots correspond to a pulse at low exhaust flow, being both at oxidation conditions. In both cases, the $\lambda$ measurements have a similar shape to the $\mathrm{CO}_{2}$ measurements, so that $\mathrm{NO}_{\mathrm{x}}$ sensors are fast enough to detect oxidation pulses through $\lambda$ measurements for the method presented. It is shown $\operatorname{in}^{23}$ that $\lambda$ measurements from $\mathrm{NO}_{\mathrm{x}}$ sensors are slower than $\lambda$ measurements from UEGO sensors, despite not being this a limiting factor for the strategy. Since it is not the scope of this paper to present a detailed dynamics study, this comparison is enough to observe that these measurements are reliable in terms of time response. Dynamics of the $\mathrm{NO}_{\mathrm{x}}$ sensors measurements are not significantly affected by ageing, as discussed in ${ }^{27}$, while no precision worsens are neither characterized.

A problem raised in Section Detection concept feasibility was the offset of the $\lambda$ measurements, which is characterized in Figure 4 and it is manually compensanted in the already commented Figures 7 and 8. Figure 9 represents the difference between the up- and downstream measurements during a WLTC test for a pair of sensors. The WLTC test was selected due to its strong dynamic conditions, which provoke continuous differences between up- and downstream $\lambda$ measurements, mixing the effects of sensors offset, engine dynamics and transport time of the species. The sensors were located initially and vice-versa to see the effect that offset can have on the strategy. As dynamics lead to a wide range of cases between up and downstream $\lambda$ measurements, the histogram of Figure 9 have both negative and positive values, which can be compared to the effect of oxidation on $\lambda$. The order of magnitude that an oxidation event produces in $\lambda$ is about 0.05 . Then, as the dynamic 

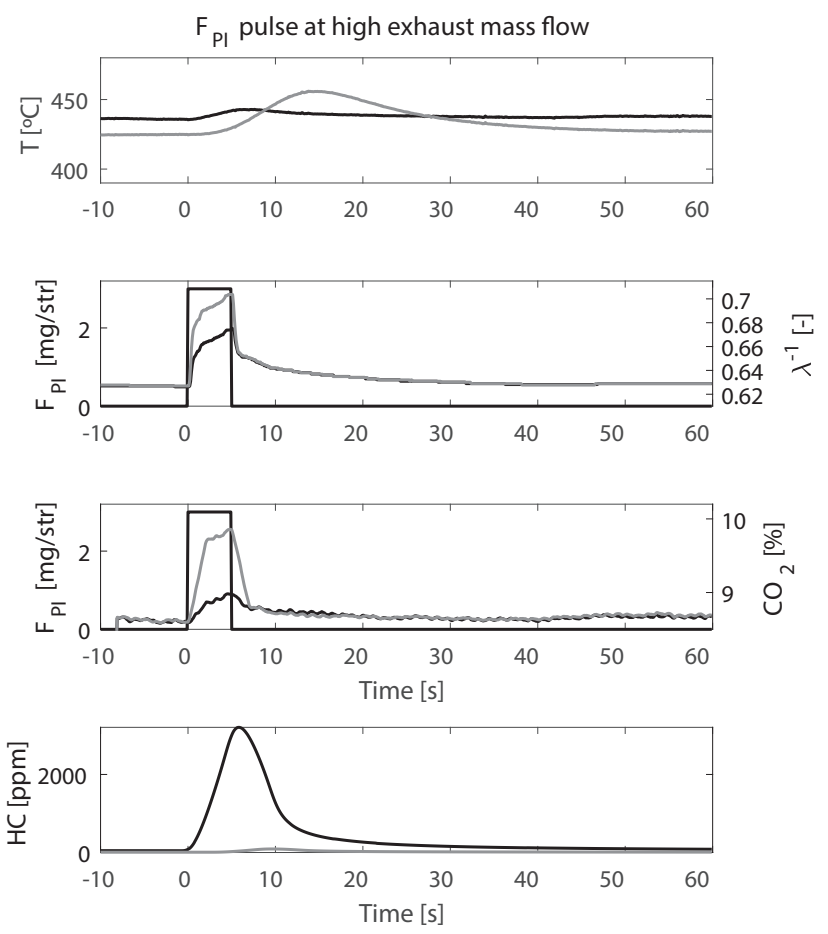
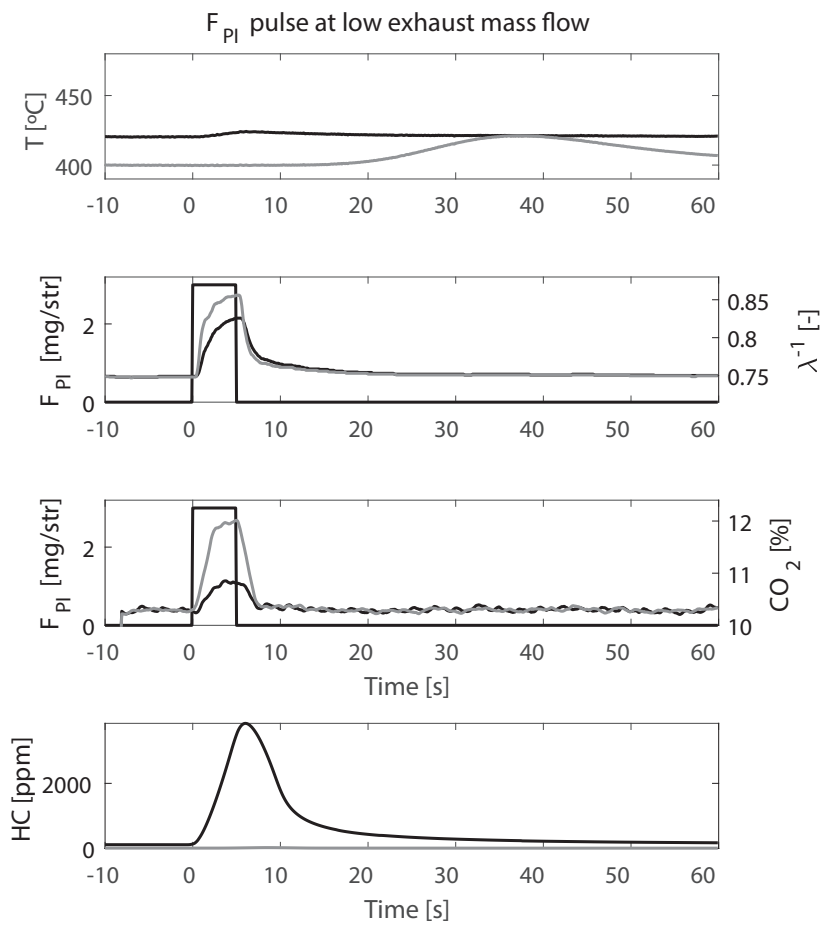

Figure 8. Analysis of $\lambda$ measurements dynamics capacities for two post-injection pulses at different exhaust mass flows, occurring oxidation at both events. In all plots, black and grey stand for upstream and downstream signals, respectively. The squared signal of medium plots represents the post-injection pulse. Offset between upstream and downstream $\lambda$ measurements is compensated.

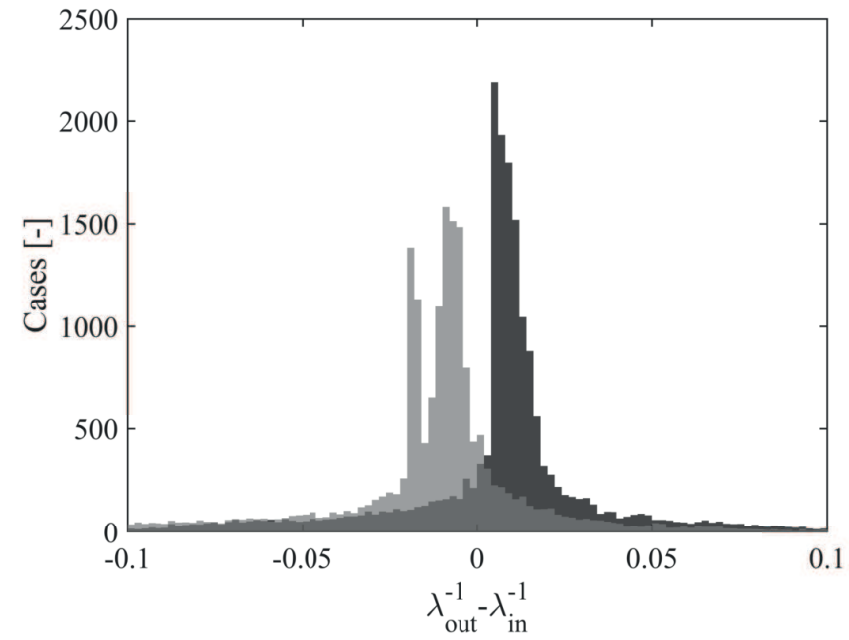

Figure 9. Offset between $\lambda_{u s}$ and $\lambda_{d s}$ measurements during a WLTC. Dark grey: Original sensors layout distribution. Light grey: Sensors located viceversa. The intermediate grey is the intersection of both histograms.

detection strategy had non-adaptive thresholds as tunable parameters, these are not valid for any pair of sensors, so it can be concluded that sensors offset distortion disable the dynamic strategy.

Finally, the $\lambda$ measurements of the $\mathrm{NO}_{\mathrm{x}}$ sensors during the fuel post-injections are analyzed here. For this purpose, the $\lambda$ measurements of Figure 7 are further detailed with measurements of the Horiba gas analyzer in Figure 10. Note that the offsets and delays of the measurements have been compensated beforehand in order to compare the pulses increments with respect to its steady value.
In the top plot, the three upstream measurements of $\lambda$ from the sensors, $\lambda_{s e n}, \lambda$ from the gas analyzer, $\lambda_{G A}$, and oxygen from the gas analyzer converted to $\lambda$ signal, $\lambda_{O_{2}, G A}$, are different. As detailed in previous section, the upstream measurements of $\lambda$ are affected by the HC species during the post-injection pulses. In this sense, the $\lambda_{\text {sen }}$ and $\lambda_{G A}$ measure the oxygen excess, while the $\lambda_{O_{2}, G A}$ represents the oxygen concentration, whose signal is converted into $\lambda$. I.e. the oxygen represented by $\lambda_{G A}$ is the oxygen represented by $\lambda_{O_{2}, G A}$ minus the oxygen that the $\mathrm{HC}$ and $\mathrm{CO}$ species would consume if they were oxidized. However, the measurements of $\lambda_{\text {sen }}$ do not match the $\lambda_{G A}$, despite these two measurements should have, theoretically, a similar signal.

The effect of $\mathrm{HC}$ in the $\lambda_{\text {sen }}$ measurement, as an oxygen excess measurement apparatus, is not accurate, and it measures more oxygen excess than it should. In fact, this experimental bias of oxygen excess, $\Delta \lambda$, is the basis of this article. I.e. the oxidation of $\mathrm{HC}$ species provokes higher peaks in the downstream $\lambda_{\text {sen }}$ signal than in the upstream $\lambda_{\text {sen }}$ measurement, which allows the detection of oxidation phases in the DOC.

For this reason, the three downstream measurements of $\lambda_{\text {sen }}, \lambda_{G A}$ and $\lambda_{O_{2}, G A}$ present similar values. In this sense, the $\lambda$ signal is not affected by the $\mathrm{HC}$ species, since these are oxidized or accumulated in the catalyst. However, the $\lambda_{d s}^{-1}$ peaks are still present at the end of the test, which are mainly due to undesired in-cylinder combustion of the fuel PI and due to $\mathrm{CO}$ oxidation.

In conclusion, if the $\lambda_{\text {sen }}$ signal were proportional to the real $\lambda$ value, it would be not possible to detect oxidation phases following the presented strategy. However, the real $\lambda_{\text {sen }}$ measurements are somewhere in between the real $\lambda$ and the $\lambda$ value that represents the actual oxygen concentration. 

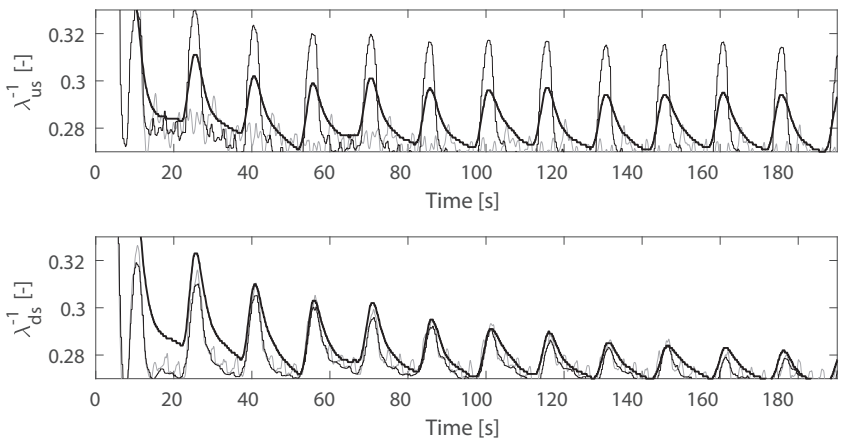

Figure 10. $\lambda$ measurements during the train of post-injection pulses of Figure 8. Offsets and delays are manually compensated. Thick black: $\lambda$ measurements of $\mathrm{NO}_{x}$ sensors, $\lambda_{\text {sen }}$. Thin black: $\lambda$ measurements of Horiba gas analyzer, $\lambda_{G A}$. Thin grey: Oxygen measured by Horiba gas analyzer converted to $\lambda$ signal, $\lambda_{O_{2}, G A}$.
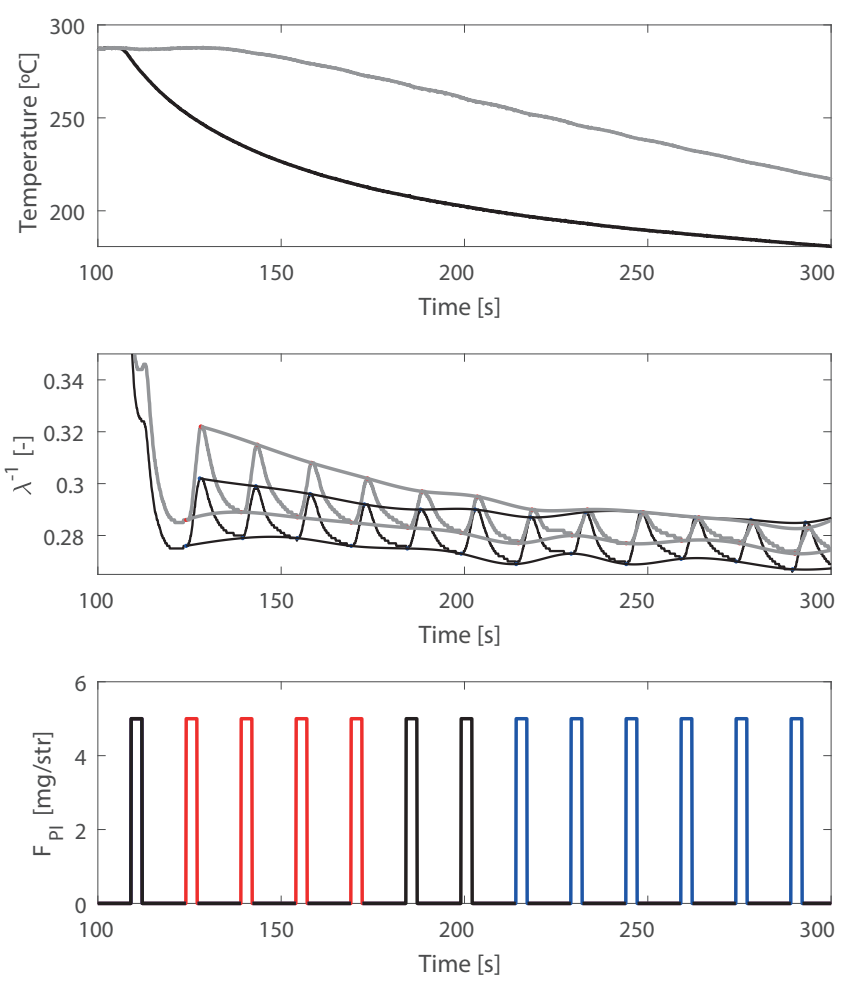

Figure 11. Method application to a 300s idle period. Black and grey colors stand for upstream and downstream measurements in temperature (top) and $\lambda$ (medium) plots. $\lambda$ signals are tunnelled in medium plot. In the $\mathrm{F}_{P I}$ plots, black stands for non-defined, red stands for oxidation and blue stands for no oxidation.

In this sense, the difference with respect to the actual $\lambda$ is sufficient and not critical, since a proper thresholds-based strategy allows the detection of oxidation phases.

\section{On-board LOT estimation}

The method to estimate the light-off temperature is detailed in this section. As stated before, idle-like conditions are used to avoid dynamics and to have a controlled decrease of temperature, while post-injections are applied. Figure 11 shows an example of the method application during an idle period of 300 s, whose initial temperature is aroud $300{ }^{\circ} \mathrm{C}$. Then, the temperature decreases to near $185^{\circ} \mathrm{C}$. During this
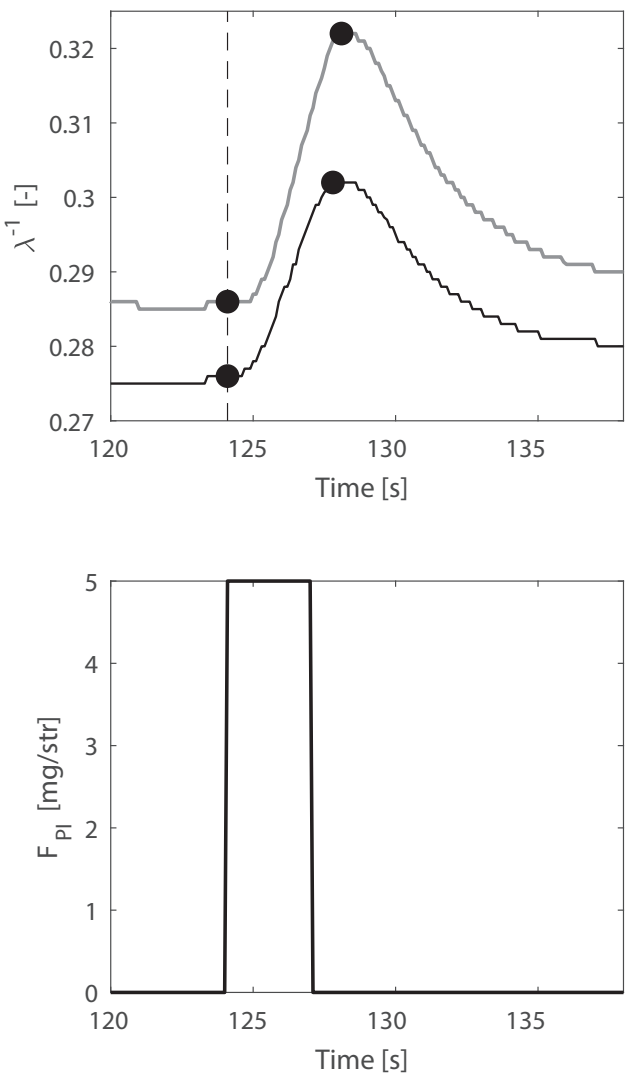

Figure 12. Initial and maximum values used in the algorithm for both up- and downstream $\lambda$ measurements during a post-injection pulse event with oxidation. Top plot: dots stand for initial and maximum values, black line stands for upstream $\lambda$, grey line stands for downstream $\lambda$ and dashed line stands for post-injection start. Bottom plot: post-injection pulse.

period, a train of post-injection pulses of $5 \mathrm{mg} / \mathrm{str}$ of fuel during 3 seconds each 15 seconds is being applied. The $\lambda$ signal is tunnelled between minimums and maximums, so it is easier to appreciate how the differences between both tunnels decrease as temperature decreases.

When a post-injection pulse is applied, a temporal window is open until the peak of $\lambda^{-1}$ is reached. Then, the initial $\lambda_{\text {ini }}^{-1}$ and peak $\lambda_{\text {peak }}^{-1}$ values obtained during this window for both up- and downstream signals are used to take a decision of the post-injection event according to equations 4 to 6 . These particular values are highlighted in Figure 12 for a post-injection pulse. If inequation 4 is true, no oxidation is observed. Inequation 5 stands for an undefined range, in which neither oxidation nor no oxidation can be ensured. Finally, inequation 6 is true when oxidation occurs. A threshold for no oxidation $\Delta \lambda_{1}$ and a threshold for oxidation $\Delta \lambda_{2}$ allow taking the decision of the pulse. Equations 4 to 6 are described next:

$$
\lambda_{d s, p e a k}^{-1}-\lambda_{d s, i n i}^{-1}-\left(\lambda_{u s, p e a k}^{-1}-\lambda_{u s, i n i}^{-1}\right)<\Delta \lambda_{1}
$$

$$
\Delta \lambda_{1}<\lambda_{d s, p e a k}^{-1}-\lambda_{d s, i n i}^{-1}-\left(\lambda_{u s, p e a k}^{-1}-\lambda_{u s, i n i}^{-1}\right)<\Delta \lambda_{2}
$$

$$
\lambda_{d s, p e a k}^{-1}-\lambda_{d s, i n i}^{-1}-\left(\lambda_{u s, p e a k}^{-1}-\lambda_{u s, i n i}^{-1}\right)>\Delta \lambda_{2}
$$


Table 2. Frequency based contrast indicator $F_{\text {ind }}$ between $\lambda_{d s}$ and $\lambda_{u s}$ peaks due to post-injection pulses.

\begin{tabular}{llllll} 
& \multicolumn{5}{c}{$F_{P I}[\mathrm{mg} / \mathrm{str}]$} \\
$F_{P I}$ time [s] & 1 & 2 & 3 & 4 & \\
\hline 0.5 & 1.17 & 1.75 & 1.55 & 1.58 & \\
1 & 1.33 & 1.22 & 2.13 & 1.74 & \\
1.5 & 1.42 & 1.40 & 1.60 & 2.25 & \\
2 & 1.64 & 1.80 & 1.63 & 2.37 & \\
3 & 1.44 & 1.72 & 1.95 & 2.04 & \\
\hline & 5 & 6 & 7 & 8 & 10 \\
\hline 0.5 & 1.85 & 1.79 & 2.07 & 1.42 & 1.15 \\
1 & 2.07 & 1.89 & 1.90 & 2.09 & 1.70 \\
1.5 & 2.18 & 2.12 & 1.94 & 2.06 & 1.96 \\
2 & $\mathbf{2 . 5 0}$ & $\mathbf{2 . 5 2}$ & 2.05 & 2.03 & 2.10 \\
3 & $\mathbf{2 . 5 4}$ & $\mathbf{2 . 4 5}$ & 2.03 & 1.94 & 2.14 \\
\hline
\end{tabular}

where $\lambda_{\text {peak }}^{-1}$ is the peak value due to the post-injection pulse and $\lambda_{i n i}^{-1}$ is the initial value of the signal when the postinjection is applied. $\lambda_{u s}^{-1}$ stands for upstream $\lambda^{-1}$, while $\lambda_{d s}^{-1}$ stands for downstream $\lambda^{-1}$.

Other techniques could be used to separate oxidation from no oxidation, like taking into consideration the frequency content of the pulse, as it is done for the pulses calibration. However, the simple method presented, based on initial values and peaks, shows enough accuracy. In Figure 11, the post-injections are coloured with the oxidation result, being the initial 4 pulses associated to oxidation, the 2 following pulses undetermined and the subsequent associated to no oxidation. The initial pulse is not identified, since it was done during the transition phase from the initial engine operating condition to idle-like condition, during which $\lambda$ is still stabilizing.

A test to characterize the required level of post-injection was carried out with different post-injections pulses, from 1 to $10 \mathrm{mg} / \mathrm{str}$, and different durations, from 0.5 to $3 \mathrm{~s}$, at idle-like conditions, characterized by no oxidation and lean mixture conditions. A spectrogram is applied to the test, in order to obtain the frequency content of each pulse with the power spectral density (PSD). For each pulse, the spectrogram is integrated between 1.7 and $2.3 \mathrm{~Hz}$, and a $10 \mathrm{~s}$ window, resulting in $P S D_{u s}$ for the upstream signal and $P S D_{d s}$ for the downstream signal. Then, the indicator $F_{\text {ind }}$ shown in the equation 7 is used to fill the Table 2. This indicator is related to the contrast between up- and downstream $\lambda$ measurements when a post-injection pulse is applied.

$$
F_{\text {ind }}=P S D_{d s} / P S D_{u s}
$$

According to Table 2, post-injections of 5 and $6 \mathrm{mg} / \mathrm{str}$ during 2 and 3 seconds have the highest contrast, being $5 \mathrm{mg} / \mathrm{str}$ and 3 seconds the best for a small difference. Less fuel post-injected could be more confused with signal noise, while more fuel post-injected would not add more differentiation between up- and downstream signals. Figure 13 shows an example of the spectrogram application for 5 pulses of $0.5,1,1.5,2$ and 3 seconds of duration and $5 \mathrm{mg} / \mathrm{str}$. As it can be appreciated in the top plot, the original $\lambda$ signals are noisy in this engine operating point, but $\lambda$ peaks can
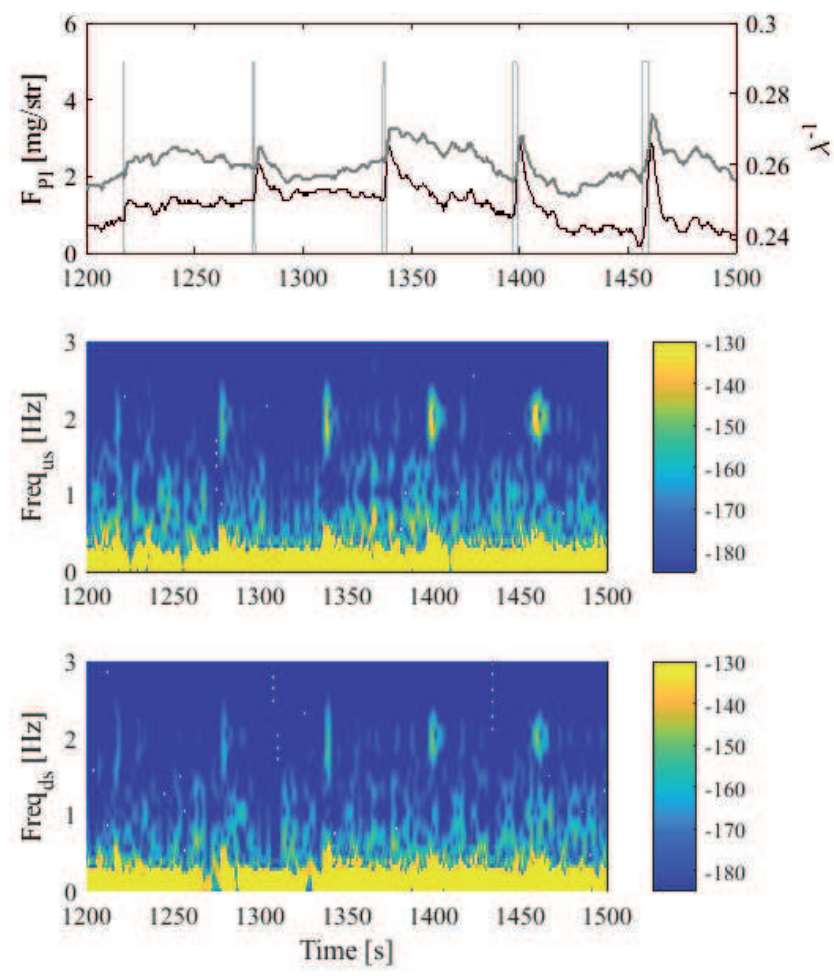

Figure 13. Spectrogram of post-injection pulses at low engine speed and low load: $1000 \mathrm{rpm}$ and 3-7 Nm of torque. Top plot: black stands for upstream, and grey stands for downstream. Spectrogram color is power spectrum density in $\mathrm{dB} / \mathrm{Hz}$.

still be appreciated. Looking at the spectrogram plots, the upstream signal peaks have more frequency content than the downstream peaks, since there is no oxidation.

The selected temperature to associate the result of the post-injection events is the upstream temperature measured by the NTC sensor. From the two measurements available, i.e. upstream and downstream, the upstream one is selected based on experimental results. Then, the upstream NTC sensor measurement leads to a temperatures distribution like Figure 14, from which LOT thresholds can be extracted. On the other hand, using the downstream measurement does not lead to a clear differentiation between oxidation and no oxidation, which may be due to the filtering process that the DOC causes on temperature. In this sense, since the DOC bed temperature is not constant over the axial length of the catalyst, a 1D thermal model could be used to have an intermediate estimation. However, no results show better strategy performance considering the downstream measurement or an intermediate estimated temperature.

A set of tests like the presented in Figure 11 was applied to generate a database. These tests are characterized by steps from high load to low load. During the high load part, the temperature raised and no post-injections were applied, and during the low load, a train of post-injections like the shown in Figure 11 was applied. In these tests, the high load part had a steady-state temperature significantly over the LOT, while the low load had a steady temperature below the LOT.

Figure 14 shows the results from the post-injection tests for the nominal and aged DOCs. As it can be observed for the nominal DOC, oxidation events start at $210^{\circ} \mathrm{C}$ and no oxidation events end at the same temperature. However, for the aged DOC, an undefined area between 235 and 

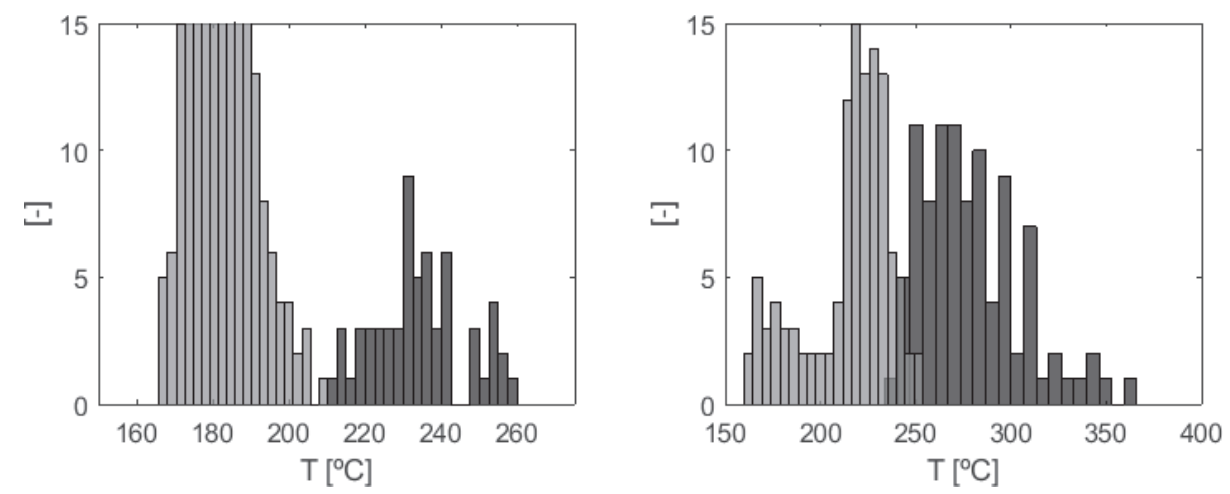

Figure 14. Databases of LOT detection strategy for the nominal (left) and the aged (right) DOCs. Dark columns: oxidation. Light columns: no oxidation.

$255^{\circ} \mathrm{C}$, in which both cases coexist can be appreciated. This phase depends on the $t_{1}$ and $t_{2}$ thresholds calibration. Increasing $t_{1}$ and $t_{2}$ thresholds separates the oxidation and no oxidation, but also increases the number of non-defined cases. Therefore, a trade-off between accuracy and number of defined cases is observed. Although the DOC used in the experiments for the paper is able to accumulate $\mathrm{HC}$ species, in case all the HC slipped from the catalyst, the downstream signal would be equal to the upstream, not interfering in the method results.

In the case of this paper, a database was generated once for the nominal DOC and once for the aged DOC. For real operating conditions, the database should be recreated at a certain time or mileage to compare results and observe the increase of LOT.

\section{Conclusions}

A on-board strategy to estimate the LOT of DOCs has been presented in this article by means of $\lambda$ and temperature sensors measurements. Despite the fact that $\lambda$ measurements should provide a measurement of the oxygen excess, they actually provide an intermediate value between the oxygen concentration and the oxygen excess, as demonstrated comparing $\lambda$ measurements from $\mathrm{NO}_{\mathrm{x}}$ sensors with gas analyzer measurements. In this sense, $\lambda_{d s}^{-1}>\lambda_{u s}^{-1}$ occurs when there is oxidation, while $\lambda_{d s}^{-1}<\lambda_{u s}^{-1}$ occurs when there is no oxidation and accumulation. Then, $\Delta \lambda_{1}$ threshold ensures oxidation, and $\Delta \lambda_{2}$ threshold ensures no oxidation, while no decision is taken in the intermediate interval between $\Delta \lambda_{1}$ and $\Delta \lambda_{2}$.

The on-board method for LOT estimation is done during idle periods, since this engine operation point provides ideal steady-state conditions to avoid sensors offsets during the post-injection pulses and provides conditions in which the upstream temperature measurement is representative of the post-injection pulses oxidation, or no oxidation, into the DOC.

In the strategy, the $\lambda$ measurements determine if there is oxidation or not in the post-injection pulses first. Next, the DOC upstream temperature is associated to the results of the post-injection pulses in order to generate a database. Then, when a long window of time has passed, the resulting database is used to determine temperature ranges of temperatures that include non-oxidation, undefined and an oxidation intervals. Finally, these ranges have to be evaluated over time to detect if the LOT increases.

\section{Acknowledgements}

The authors acknowledge the support of Spanish Ministerio de Economía, Industria y Competitividad through project TRA2016-78717-R.

\section{References}

1. Regulation EC. No 136/2014. Official Journal of the European Union, 2014.

2. Regulation EC. No 459/2012. Official Journal of the European Union, 2012.

3. Guardiola C, Pla B, Piqueras P et al. Model-based passive and active diagnostics strategies for diesel oxidation catalysts. Applied Thermal Engineering 2017; 110: 962-971.

4. Regulation EC. No 2016/646. Official Journal of the European Union, 2016.

5. Blanco-Rodriguez D, Vagnoni G and Holderbaum B. EU6 CSegment Diesel vehicles, a challenging segment to meet RDE and WLTP requirements. IFAC-PapersOnLine 2016; 49(11): 649 - 656. 8th IFAC Symposium on Advances in Automotive Control AAC 2016.

6. Delphi. Worldwide emission standards. Technical report, Delphi, 2017.

7. Posada F and German J. Review of LDV OBD requirements under the European, Korean and Californian emissions programs. The international council on clean transportation 2016; .

8. Bartley GJ. Identifying limiters to low temperature catalyst activity. In SAE Technical Paper. SAE International.

9. Ye S, Yap YH, Kolaczkowski ST et al. Catalyst light-off experiments on a diesel oxidation catalyst connected to a diesel engine-methodology and techniques. Chemical Engineering Research and Design 2012; 90(6): 834 - 845.

10. Li J, Szailer T, Watts A et al. Investigation of the impact of realworld aging on diesel oxidation catalysts. SAE Int J Engines 2012; 5: 985-994. DOI:10.4271/2012-01-1094.

11. Nakane $T$, Ikeda $M$, Hori $M$ et al. Investigation of the aging behavior of oxidation catalysts developed for active DPF regeneration systems. In SAE Technical Paper. SAE International.

12. Wiebenga MH, Kim CH, Schmieg SJ et al. Deactivation mechanisms of Pt/Pd-based diesel oxidation catalysts. Catalysis 
Today 2012; 184(1): 197 - 204. Catalytic Control of LeanBurn Engine Exhaust Emissions.

13. Ruetten O, Pischinger S, Kuepper $\mathrm{C}$ et al. Catalyst aging method for future emissions standard requirements. In $S A E$ Technical Paper. SAE International.

14. Mallamo F, Longhi S, Millo F et al. Modeling of diesel oxidation catalysts for calibration and control purpose. International Journal of Engine Research 2014; 15(8): 965979.

15. Schultz R and Meckl PH. Light-off temperature shift for catalyzed diesel particulate filter on-board diagnostics. In $S A E$ Technical Paper. SAE International.

16. Nieuwstadt MV and Upadhyay D. Control of urea SCR systems for US diesel applications. IFAC-PapersOnLine 2011; 66(4): 655-663.

17. Mohammadpour J, Franchek M and Grigoriadis K. A survey on diagnostic methods for automotive engines. International Journal of Engine Research 2012; 13(1): 41-64.

18. Tourlonias $P$ and Koltsakis G. Model-based comparative study of Euro 6 diesel aftertreatment concepts, focusing on fuel consumption. International Journal of Engine Research 2011; 12(3): 238-251.

19. Van Nieuwstadt M and Upadhyay D. Diagnosis of a urea scr catalytic system, 2005. US Patent 6.925.796.

20. Nieuwstadt MV, Upadhyay D and Yuan F. Diagnostics for diesel oxidation catalysts. In SAE Technical Paper. SAE International. DOI:10.4271/2005-01-3602.

21. Hommen G, Kupper F and Seykens X. Robust, model-based urea dosing control for SCR aftertreatment systems using a cross-sensitive tailpipe nox sensor. In SAE Technical Paper Series. SAE International.

22. Guardiola C, Martín J, Pla B et al. Cycle by cycle NOx model for diesel engine control. Applied Thermal Engineering 2017; 110: 1011-1020.

23. Guardiola C, Pla B, Blanco-Rodriguez D et al. A bias correction method for fast fuel-to-air ratio estimation in diesel engines. Proceedings of the Institution of Mechanical Engineers, Part D: Journal of Automobile Engineering 2013; 227(8): 1099-1111.

24. Moos R. A brief overview on automotive exhaust gas sensors based on electroceramics. International Journal of Applied Ceramic Technology 2005; 2(5): 401-413.

25. Regulation EC. No 692/2008. Official Journal of the European Union, 2008.

26. Guardiola C, Dolz V, Pla B et al. Fast estimation of diesel oxidation catalysts inlet gas temperature. Control Engineering Practice 2016; 56: 148-156.

27. Galindo J, Serrano J, Guardiola C et al. An on-engine method for dynamic characterisation of NOx concentration sensors. Experimental Thermal and Fluid Science 2011; 35(3): 470476. 